\title{
NECESSITY OF MENTAL HEALTH PACKAGE OF THE ALBANIAN STUDENT OF MEDICINE AND YOUNG DOCTORS
}

\author{
Admir Nake ${ }^{1 *}$ \\ $1 *$ University of Medicine, Tirana, Albania;
}

*Correspondence author: Admir Nake, e-mail: admir.nake@ umed.edu.al; adi.nake@yahoo.com;

Received August, 2018; Accepted August, 2018; Published September, 2018;

DOI: https://doi.org/10.31407/ijees8420

UOI license: http://u-o-i.org/1.01/ijees/87261641

\begin{abstract}
Every two-three years the requests change during the years of studies in University of Medicine. The first two years are adaption to the new point of view of studies, relationships, and environmental and micro-environment changes. This immediate change of reality, without right adaption can lead to stress or short-term or long-term depressive episodes. The second two years can pass with unexpected changes and pressure because of clinical situations and disciplines and a lot of hours of studies. The last two years can pass with the pressure of getting married, finding a job, successful finishing of faculty, selecting right profile or specialization and being a doctor. Stigma, mobbing and competition as one of the most competitive profession are continuous challenges of doctors, especially young doctors. Sensibilities to create The Mental Health Package of the Albanian student of medicine and young doctor. Students of University of Medicine are inclusive target groups with age and gender feature. This theoretically and practically package, will fight masked depression, depression episodes, depression or minimizing stress during the six years of University of Medicine and young doctors. Students of University of Medicine and young doctors need special and professional instructions and support, through The Mental Health Package of the( Albanian )Student of Medicine, to begin, to go on and finish full of success and without stress or depression, their long and different year of study and to be a successful young doctors.
\end{abstract}

Key words: students, medicine, young doctors, stigma, burn out 